\title{
Linguistic and metalinguistic categories in second language learning
}

KAREN ROEHR*

\section{Abstract}

This paper discusses proposed characteristics of implicit linguistic and explicit metalinguistic knowledge representations as well as the properties of implicit and explicit processes believed to operate on these representations. In accordance with assumptions made in the usage-based approach to language and language acquisition, it is assumed that implicit linguistic knowledge is represented in terms of flexible and context-dependent categories which are subject to similarity-based processing. It is suggested that, by contrast, explicit metalinguistic knowledge is characterized by stable and discrete Aristotelian categories which subserve conscious, rule-based processing. The consequences of these differences in category structure and processing mechanisms for the usefulness or otherwise of metalinguistic knowledge in second language learning and performance are explored. Reference is made to existing empirical and theoretical research about the role of metalinguistic knowledge in second language acquisition, and specific empirical predictions arising out of the line of argument adopted in the current paper are put forward.

Keywords: categorization; explicit and implicit knowledge; metalinguistic knowledge; second language learning, usage-based model.

\section{Introduction}

This article is concerned with the role of metalinguistic knowledge, or explicit knowledge about language, in the area of second language acquisition (SLA). It is situated within a cognitive-functional approach to language and language learning, in the belief that our understanding of an essentially pedagogical notion-metalinguistic knowledge - may be enhanced if we consider this notion in terms of a specific linguistic theory, 
that is, the usage-based model of language. In this way, light can be shed on a concept which is of interest to second language (L2) teachers, adult language learners themselves, and last but certainly not least, applied linguists of all theoretical persuasions, including cognitive linguists with a pedagogical outlook (e.g., Achard and Niemeier 2004; Boers and Lindstromberg 2006).

In this paper, I argue that while implicit linguistic knowledge is characterized by exemplar-based categories, explicit metalinguistic knowledge relies on Aristotelian categories. Exemplar-based categories are flexible, highly contextualized, and subject to prototype effects, whereas Aristotelian categories are stable, discrete, and clearly delineated. These characteristics can be illustrated briefly with the help of the following examples (from Taylor 2003): (1) The Pope is a bachelor. (2) Her husband is an unrepentant bachelor. ${ }^{1}$ If the construction bachelor is considered in terms of Aristotelian category structure, i.e., if it is defined by means of primitive binary features such as +adult, +male, -married, etc., sentence (1) would be judged semantically acceptable, while sentence (2) would have to be regarded as semantically anomalous. Conversely, if the construction bachelor is considered in terms of exemplar-based category structure, categorization by means of primitive binary features no longer applies. Instead, specific attributes associated with the category [BACHELOR] can be perspectivized in accordance with the linguistic and cultural context provided by the sentences in which the construction appears, whereas other attributes may be filtered out. Thus, sentence (1) seems somewhat odd, since bachelorhood is taken for granted in a pope. Sentence (2), by contrast, is no longer anomalous, since certain behavioural attributes associated with the (idealized) prototype of an unmarried man are highlighted; at the same time, the attribute associated with the marital status of a prototypical bachelor is temporarily ignored.

In addition to positing qualitatively distinct category structures, I assume that the processing mechanisms operating on implicit linguistic and explicit metalinguistic knowledge representations are qualitatively different. While implicit linguistic knowledge is stored in and retrieved from an associative network during parallel distributed, similarity-based processing, explicit metalinguistic knowledge is processed sequentially with the help of rule-based algorithms. I suggest that these distinctions between linguistic and metalinguistic knowledge representations and processes affect the way in which the two types of knowledge can be used in L2 learning and performance.

Indeed, it appears that the proposed conceptualization of linguistic and metalinguistic knowledge in terms of different category structures and associated differences in processing mechanisms can help explain available 
findings from the area of SLA which are indicative of both facilitative potential and apparent limitations of metalinguistic knowledge in L2 learning and performance. Moreover, if read in conjunction with existing research, the proposed conceptualization allows for the formulation of specific predictions about the use of metalinguistic knowledge in L2 learning, both at a general level and for particular types of language learners.

The article is organized as follows: Section 2 provides definitions of the main constructs under discussion, that is, explicit and implicit knowledge, explicit and implicit learning, pedagogical grammar, and metalinguistic knowledge. In Section 3, assumptions about the nature of implicit linguistic knowledge commonly made by researchers working in a usage-based paradigm are outlined. Section 4 contains a summary and evaluation of key empirical and theoretical research in relation to the role of explicit knowledge in language acquisition, with a strong emphasis on L2 learning. Section 5 puts forward the proposal which is at the core of the current paper, with the argument focusing on the contrasting category structures of implicit linguistic knowledge and explicit metalinguistic knowledge as well as differences in processing mechanisms associated with these. Section 6 details empirical predictions that emerge from the argument put forward in the current paper. Section 7 offers a brief conclusion.

\section{Construct definitions}

Explicit knowledge is defined as declarative knowledge that can be brought into awareness and that is potentially available for verbal report, while implicit knowledge is defined as knowledge that cannot be brought into awareness and cannot be articulated (Anderson 2005; Hulstijn 2005). Accordingly, explicit learning refers to situations "when the learner has online awareness, formulating and testing conscious hypotheses in the course of learning". Conversely, implicit learning "describes when learning takes place without these processes; it is an unconscious process of induction resulting in intuitive knowledge that exceeds what can be expressed by learners" (N. Ellis 1994: 38-39; see also N. Ellis 1996; Hulstijn 2005).

It is assumed that focused attention is a necessary requirement for bringing representations or processes into conscious awareness, i.e., for knowledge or learning to be explicit. In accordance with existing research, three separable but associated attentional sub-processes are assumed, that is, alertness, orientation, and detection (Schmidt 2001; Tomlin and Villa 1994). In this conceptualization of attention, alertness refers to an individual's general readiness to deal with incoming stimuli; orientation 
concerns the allocation of resources based on expectations about the particular class of incoming information; during detection, attention focuses on specific details. Detection is thought to require more attentional resources than alertness and orientation, and to enable higher-level processing (Robinson 1995). Stimulus detection may occur with or without awareness. If coupled with awareness, stimulus detection is equivalent with noticing, which is defined as awareness in the sense of (momentary) subjective experience (Schmidt 1990, 1993, 2001). Proponents of the socalled noticing hypothesis argue that noticing, or attention at the level of awareness, is required for L2 learning to take place.

It is worth noting that the concepts of attention, noticing, and awareness, as well as their application in SLA, remain controversial (for critical reviews, see, for instance, Robinson 2003; Simard and Wong 2001). Nevertheless, a working definition is needed to allow for a clear discussion. Thus, for the purpose of the present article, it is assumed that the fine line between focused attention in the sense of stimulus detection and focused attention in the sense of noticing can be regarded as the threshold of conscious awareness, that is, the point of interface between implicit and explicit processes and representations.

First and foremost, the present paper is concerned with the notion of metalinguistic knowledge. Metalinguistic knowledge is a specific type of explicit knowledge, that is, an individual's explicit knowledge about language. Accordingly, L2 metalinguistic knowledge is an individual's knowledge about the L2 they are attempting to learn. The term metalinguistic knowledge tends to be used in applied linguistics research concentrating on L2 learning and teaching (e.g., Alderson et al. 1997; Bialystok 1979; Elder and Manwaring 2004), and it is closely related to applied linguists' conceptualization of pedagogical grammar (e.g., McDonough 2002; Saporta 1973; Towell 2002). Pedagogical grammar has been described as "a cover term for any learner- or teacher-oriented description or presentation of foreign language rule complexes with the aim of promoting and guiding learning processes in the acquisition of that language" (Chalker 1994: 34, quoting Dirven 1990). It is worth noting that, in discussions of pedagogical grammar, the term grammar is used in a broad sense as referring to any aspect of language that can be described systematically; it is therefore not restricted to morphosyntactic phenomena.

In sum, the notion of metalinguistic knowledge is concerned with a learner's explicit mental representations, while the notion of pedagogical grammar is concerned with explicit written or oral descriptions of linguistic systematicities which can be presented to a learner as a source of information about the L2. Accordingly, a learner's metalinguistic knowledge may arise from encounters with pedagogical grammar, e.g., through 
textbooks and/or through exposure to rule-based or other types of formfocused instruction (R. Ellis 2001; Sanz and Morgan-Short 2005). By the same token, pedagogical grammar has arisen from the metalinguistic knowledge of applied linguists, L2 teachers, and materials designers. Thus, while the labels of metalinguistic knowledge and pedagogical grammar are used to denote, respectively, an individual's mental representations and written or oral instructional aids, the two notions are similar to the extent that they are both explicit by definition and that the latter can give rise to the former as well as vice versa.

As the argument presented in what follows is concerned with differences in category structure between explicit and implicit knowledge, the question of whether a learner's explicit knowledge has been derived bottom-up through a process of analysis of the linguistic input or whether it has been acquired top-down through formal study of grammar textbooks is not of immediate relevance. In other words, for the purpose of the current discussion, it does not matter whether explicit knowledge has arisen from implicit knowledge, e.g., when an L2 learner, perhaps after prolonged experience with the L2, discovers certain systematicities and arrives at a pedagogical grammar rule of their own, which is represented as metalinguistic knowledge and can be articulated, or whether explicit knowledge is assimilated from the environment, e.g., when an L2 learner listens to a teacher's explanation drawing on a pedagogical grammar rule and memorizes this information as metalinguistic knowledge. In either scenario, the defining characteristics, including the internal category structure, of the metalinguistic knowledge held by the learner remain the same, as will become apparent in Section 5 below.

It is acknowledged that there may be pedagogically relevant differences between internally induced metalinguistic knowledge and metalinguistic knowledge gleaned from externally presented pedagogical grammar that are of practical interest to teachers and learners in the L2 classroom. I am not aware of any empirical research pertaining to this specific issue, but one could hypothesize, for instance, that pedagogical grammar rules presented to the learner are more accurate than metalinguistic knowledge induced bottom-up by the learner him/herself, since the cumulative knowledge of the applied linguistics community is based on more extensive language experience than the average individual learner has been able to gather. Alternatively, one could hypothesize that metalinguistic knowledge derived by the learner him/herself is more relevant to the individual's L2 learning situation than one-size-fits-all pedagogical grammar rules acquired from a commercially produced textbook. These questions, though clearly interesting in themselves, do not impact on the theoretical argument put forward here, however. 
Finally, it is worth noting that rule-based or other types of formfocused instruction occur not only in the L2 classroom, but also in the context of laboratory studies. Reports of such empirical studies as well as theoretical papers with a psycholinguistic orientation (e.g., DeKeyser 2003; N. Ellis 1993; Robinson 1997) tend not to use the terms formfocused instruction, pedagogical grammar, or metalinguistic knowledge; instead, they refer more generally to explicit learning conditions and learners' explicit knowledge. However, explicit learning conditions drawing on learners' explicit knowledge typically require knowledge about the L2, i.e., metalinguistic knowledge. Hence, the notion of metalinguistic knowledge is of relevance to L2 learning and L2 teaching, as well as to psycholinguistically oriented and applied SLA research.

In the context of the present article, metalinguistic knowledge is defined as a learner's explicit or declarative knowledge about the syntactic, morphological, lexical, pragmatic, and phonological features of the L2. Metalinguistic knowledge includes explicit knowledge about categories as well as explicit knowledge about relations between categories (R. Ellis 2004; $\mathrm{Hu}$ 2002; Roehr 2007). Metalinguistic knowledge can vary in terms of specificity and complexity, but it minimally involves either a schematic category or a relation between two categories, specific or schematic. Metalinguistic knowledge relies on Aristotelian categories, i.e., categories that are stable and discrete. These categories subserve sequential, rule-based processing.

In the following sections, these proposed characteristics of metalinguistic knowledge will be explained and exemplified. I will begin by comparing and contrasting the characteristics of explicit metalinguistic knowledge with the characteristics of implicit linguistic knowledge as conceptualized in the usage-based model of language.

\section{Implicit linguistic knowledge in the usage-based model}

Within the framework of cognitive-functional linguistics, the usage-based model makes several fundamental assumptions about the nature of language: First, interpersonal communication is seen as the main purpose of language. Second, language is believed to be shaped by our experience with the real world. Third, language ability is regarded as an integral part of general cognition. Fourth, all linguistic phenomena are explained by a unitary account, including morphology, syntax, semantics, and pragmatics. Hence, at the most general level, the usage-based model characterizes language as a quintessentially functional, input-driven phenomenon (e.g., Bybee and McClelland 2005; Goldberg 2003; Tomasello 1998). Two specific theoretical consequences arising from these general premises 
are particularly relevant to the current discussion, namely, first, the process of categorization and the sensitivity of knowledge representations to context and prototype effects, and second, the notion of linguistic constructions as conventionalized form-meaning pairings varying along the parameters of specificity and complexity.

In the usage-based model, the representation and processing of language is understood in terms of general psychological mechanisms such as categorization and entrenchment, with the former underlying the latter. Entrenchment refers to the strengthening of memory traces through repeated activation. Categorization can be defined as a comparison between an established structural unit functioning as a standard and an initially novel target structure (Langacker 1999, 2000). In view of wellestablished empirical evidence from the area of cognitive psychology (Rosch and Lloyd 1978; Rosch and Mervis 1975), it is accepted that cognitive categories are subject to prototype effects, which are assumed to apply in equal measure to conceptual and linguistic knowledge (Dirven and Verspoor 2004; Taylor 2003; Tomasello 2003). A prototype can be defined as the best example of a category, i.e., prototypical members of cognitive categories have the largest number of attributes in common with other members of the category and the smallest number of attributes which also occur with members of neighbouring categories. In terms of attributes, prototypical members are thus maximally distinct from the prototypical members of other categories. To illustrate by means of a well-known example, ROBIN or MAGPIE are prototypical members of the category [BIRD] for (British) speakers of English, while PENGUIN constitutes a marginal category member (Ungerer and Schmid 1996).

Categorization is influenced by the frequency of exemplars in the input as well as by the recency and context of encounters with specific exemplars (N. Ellis 2002a, 2002b). As the parameters of frequency, recency, and context interact, specific memory traces may be more or less entrenched and hence more or less salient and accessible for retrieval (Murphy 2004). In addition, exemplars encountered in the input may be more or less similar to exemplars encountered previously. Accordingly, category membership is often a matter of degree and cannot normally be understood as a clear-cut yes/no distinction. It follows from this that category boundaries may be fuzzy, and that categories may merge into one another (Langacker 1999, 2000).

Two theoretical approaches to categorization are compatible with the usage-based assumptions outlined in the previous paragraphs, that is, the prototype view and the exemplar view (Murphy 2004). In its pure form, the prototype view holds that concepts are represented by schemas, i.e., structured representations of cognitive categories. Schemas contain 


\section{K. Roehr}

information about both attributes and relations between attributes that characterize a certain category. Conversely, the exemplar view, in its pure form, posits that our mental representations never encompass an entire concept. Instead, an individual's concept of a category is the set of specific category members they can remember, and there is no summary representation. In this view, categorization is determined not only by the number of exemplars a person remembers, but also by the similarity of a new exemplar to exemplars already held in memory.

While the prototype and exemplar views may be incompatible in their pure forms, they share a sufficiently large number of characteristics to allow for a hybrid model to be formulated which includes both schemabased and exemplar-based representations (Abbot-Smith and Tomasello 2006; Langacker 2000). As a hybrid model is not only compatible with usage-based assumptions, but also particularly informative for accounts of language learning and use, it is adopted in the current paper.

According to the hybrid model, all learning is initially exemplar-based. As experience with the input grows and as repeated encounters with known exemplars gradually change our mental representations of these exemplars, it is believed that, ultimately, abstractions over instances are derived (Kemmer and Barlow 2000; Taylor 2002). These abstractions are in fact schemas. Schema formation can be defined as "the emergence of a structure through reinforcement of the commonality inherent in multiple experiences", while, at the same time, experiential facets which do not recur are filtered out. Correspondingly, a schema is "the commonality that emerges from distinct structures when one abstracts away from their points of difference by portraying them with lesser precision and specificity" (Langacker 2000: 4).

To illustrate with the help of a linguistic example, a large number of encounters with specific utterances such as I sent my mother a birthday card and Harry is sending his friend a parcel lead to entrenchment, i.e., the strengthening of memory traces for the form-meaning associations constituting these constructions. Gradually, constructional subschemas such as send-[NP]-[NP] and finally the wholly general ditransitive schema [V]-[NP]-[NP] are abstracted. Entrenched constructions, both general and specific, are described as conventional units. Accordingly, a speaker's linguistic knowledge can be defined as "a structured inventory of conventional linguistic units" (Langacker 2000: 8).

Crucially, the hybrid view argues that representations of specific exemplars can be retained alongside more general schemas subsuming these exemplars. Put differently, specific instantiations of constructions and constructional schemas at varying levels of abstraction exist alongside each other, so that the same linguistic patterns are potentially represented 
in multiple ways. Thus, linguistic knowledge is represented in a vast, redundantly organized, hierarchically structured network of form-meaning associations.

Conventional linguistic units, or constructions, are viewed as inherently symbolic (Kemmer and Barlow 2000; Taylor 2002), so that constructions at all levels of abstraction are pairings of form and meaning (Goldberg 2003: 219). Hence, even though a constructional schema at the highest level of abstraction such as the English ditransitive [V]-[NP]-[NP] no longer contains any specific lexical items, it is still endowed with constructional meaning. Accordingly, a construction is always more than the sum of its parts; beyond symbolizing the meanings and relations of its constituents, it has its own semantic profile (Langacker 1991, 2000). For instance, at the most general level, the semantics of the English ditransitive schema [v]-[NP]-[NP] are captured by the notions of transfer and motion (Goldberg 1995, 1999, 2003).

To reiterate, the unitary approach to language which characterizes the usage-based model is applied both at the level of cognition and at the level of linguistic structure itself. Hence, syntax, morphology, and the lexicon are all accounted for by the same system (Bates and Goodman 2001; Langacker 1991, 2000; Tomasello 1998); they are regarded as differing in degree rather than as differing in kind. Syntax, morphology, and the lexicon are conceptualized as a graded continuum of conventional linguistic units, or constructions, varying along the parameters of specificity and complexity, as shown in Figure $1 .^{2}$

As Figure 1 indicates, schematic and complex constructions such as the ditransitive [v]-[NP]-[NP] occupy the area traditionally referred to as syntax. Words such as send or above are both minimal and specific and occupy the area traditionally labelled lexicon. Morphemes such as English plural $-s$ or regular past tense -ed are situated at the centre of the two clines, since instances of morphology are neither entirely specific nor entirely schematic; by the same token, they are neither truly minimal nor truly complex, but they are always bound. Lexical categories like [NOUN], [VERB], and [ADJECTIVE] are minimal but schematic, while idioms such as kick the bucket tend to be both complex and specific in that they allow for little variation. The example kick the bucket only permits verb inflection for person and tense, for instance, and thus ranges high on the specificity scale. At the same time, the construction kick the bucket can be considered as more complex than the constructions send or above because the latter cannot be broken down any further.

To summarize, the usage-based model assumes that categorization is a key mechanism in language representation, learning, and use. As linguistic knowledge is regarded as an integral part of cognition, it is accepted 


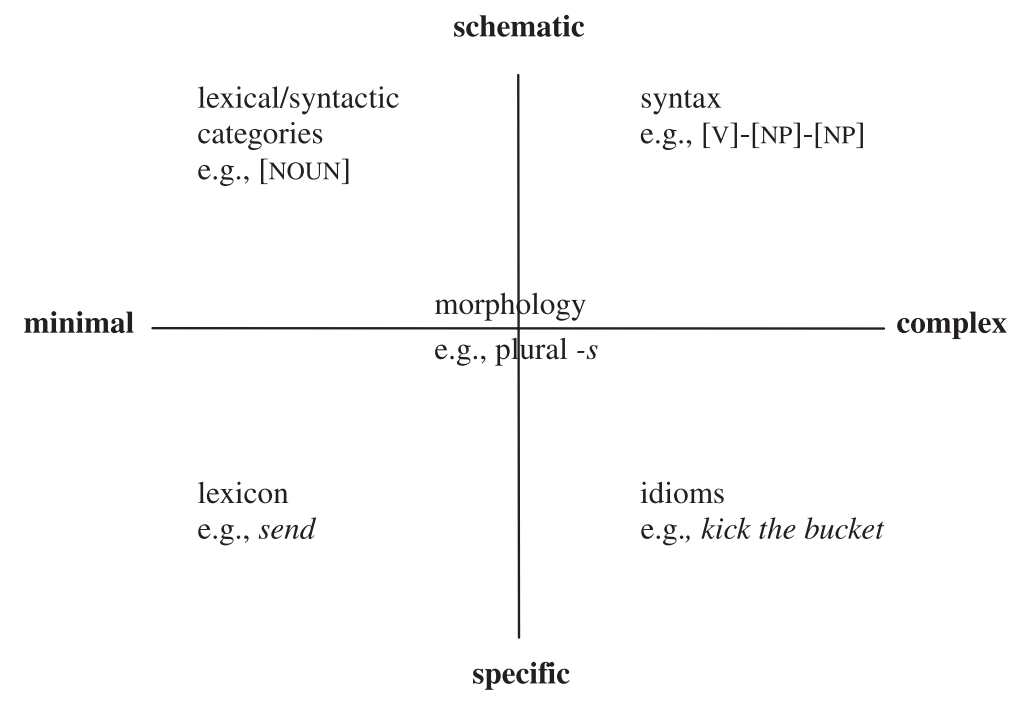

Figure 1. Linguistic constructions in the specificity/complexity continuum

that both conceptual and linguistic categories are subject to context and prototype effects. Linguistic knowledge is conceptualized in terms of constructions, i.e., conventionalized form-meaning units varying along the parameters of specificity and complexity. Crucially, these assumptions underlie the usage-based account of implicit phenomena of language representation, acquisition, and use. The role of explicit phenomena, in particular as studied in the field of SLA, is the focus of the next section.

\section{Explicit knowledge in language learning}

The notion of explicit knowledge has consistently attracted the interest of researchers in the areas of SLA and applied linguistics more generally. Over the past two decades in particular, this interest has generated an impressive amount of both empirical and theoretical research. Depending on whether researchers take a primarily educational or a primarily psycholinguistic perspective, empirical studies have drawn on a variety of correlational and experimental research designs, investigating the relationship between L2 learners' linguistic proficiency and their metalinguistic knowledge, the role of explicit knowledge in instructed L2 learning, and the effects of implicit versus explicit learning conditions on the acquisition of selected L2 constructions. 
The most uncontroversial cumulative finding resulting from this body of research has borne out the prediction that attention (in the sense of stimulus detection) is a necessary condition for the learning of novel input (Doughty 2003; N. Ellis 2001, 2003; MacWhinney 1997). Moreover, it has been found that form-focused instructional intervention is more effective than mere exposure to L2 input (Doughty 2003; R. Ellis 2001, 2002; Norris and Ortega 2001). As it is the intended purpose of all types of formfocused instruction to direct learners' attention to relevant form-meaning associations in the linguistic input, this is not a surprising outcome.

Beyond the well-substantiated claim that attention in the sense of stimulus detection is a necessary requirement for input to become intake, the picture is much less clear. In other words, findings regarding the role of explicit knowledge, i.e., knowledge above the threshold of awareness, yield a more complex and sometimes even apparently contradictory pattern of evidence. As it is beyond the scope of this paper to present an exhaustive review of the large body of research that has been carried out in the preceding decades, the following summary is deliberately brief and focused exclusively on representative studies that are directly relevant to the current discussion (for more comprehensive recent reviews of the literature, see DeKeyser 2003; R. Ellis 2004). In particular, work which illustrates the sometimes contrasting nature of findings and conclusions as well as work which emphasizes the complex interplay of variables in language learning processes has been selected.

Empirical research concerned with metalinguistic knowledge in SLA has led to at least two results that highlight the potential benefits of explicit knowledge and learning. First, learners' metalinguistic knowledge and their L2 linguistic proficiency have been found to correlate positively and significantly, even though the strength of the relationship varies between studies, ranging from a moderate 0.3 to 0.5 (e.g., Alderson et al. 1997; Elder et al. 1999) to between 0.6 and 0.7 (Elder and Manwaring 2004), and, reported most recently, up to 0.8 (Roehr 2007). Thus, there is evidence for an overall association between higher levels of learner awareness, use of metalinguistic knowledge, and successful L2 performance (Leow 1997; Nagata and Swisher 1995; Rosa and O'Neill 1999). Second, learners' use of metalinguistic knowledge when resolving formfocused L2 tasks has been found to be associated with consistent and systematic performance (Roehr 2006; Swain 1998).

While these findings are indicative of a generally facilitative role for explicit knowledge about the L2, empirical evidence likewise demonstrates that use of metalinguistic knowledge by no means guarantees successful L2 performance. For instance, Doughty (1991) found equal gains in performance across two experimental groups comprising 20 university-level 
learners of L2 English from various L1 backgrounds. Focusing on restrictive relative clauses (e.g., I know the people who you talked with), learners receiving meaning-oriented instruction with enhanced input and learners exposed to rule-oriented instruction with explicit explanation of the targeted L2 construction showed equal gains in performance-a finding which suggests that metalinguistic explanations may be unnecessary.

By the same token, Sanz and Morgan-Short (2004) found support for the null hypothesis that providing learners with explicit information about the targeted L2 construction either before or during exposure to input-based practice would not affect their ability to interpret and produce L2 sentences containing the targeted L2 construction, as long as learners received structured input aimed at focusing their attention appropriately. The study was carried out with 69 L1 English learners of L2 Spanish and concentrated on preverbal direct object pronouns. The researchers concluded that structured input practice which made linking form and meaning task-essential, as proposed in processing instruction (VanPatten 1996, 2004), appeared to be sufficient for successful learning. Additional explicit information about the targeted L2 construction did not enhance participants' performance any further.

The ambivalent relationship between use of metalinguistic knowledge and successful L2 performance was likewise underlined by Green and Hecht (1992), Camps (2003), and Roehr (2006). Green and Hecht (1992) report a study with $300 \mathrm{~L} 1$ German learners of L2 English which targeted the use of various morphosyntactic features such as tense and word order. While successful metalinguistic rule formulation typically co-occurred with the successful correction of errors instantiating the rules in question, it was also found that successful error correction could be associated with the formulation of incorrect rules, or no rule knowledge at all.

In a study involving $74 \mathrm{~L} 1$ English learners of L2 Spanish focusing on third-person direct object pronouns, Camps (2003) collected both concurrent and retrospective verbal protocol data. He found that references to the targeted L2 construction co-occurred with accurate performance in 92 percent of cases; yet, no reference to the targeted L2 construction still co-occurred with accurate performance in 69 percent of cases. Thus, despite providing additional benefits in some cases, use of explicit knowledge appears to have been far from necessary.

Roehr (2006) studied retrospective verbal reports from ten L1 English learners of L2 German, which were obtained immediately after the completion of form-focused tasks targeting adjectival inflection. She found that although reported use of metalinguistic knowledge co-occurred more frequently with successful than with unsuccessful item resolution overall, fully correct use of metalinguistic knowledge still co-occurred 
with unsuccessful item resolution in 22 percent of cases. Along similar lines, anecdotal evidence from the L2 classroom suggests that, on occasion, learners may use their metalinguistic knowledge to override more appropriate intuitive responses based on implicit linguistic knowledge (Gabrielatos 2004).

Theoretically oriented work concerned with metalinguistic knowledge has mainly sought to identify the defining characteristics of the concept of explicit knowledge as well as the facilitative potential of such knowledge in SLA. The most substantial contribution to establishing the defining characteristics of metalinguistic knowledge has arguably been made by R. Ellis $(2004,2005,2006)$, according to whom explicit L2 knowledge is represented declaratively, characterized by conscious awareness, and verbalizable, as mentioned in the construct definition presented in Section 2 above. Moreover, explicit L2 knowledge is said to be learnable at any age, given sufficient cognitive maturity. As explicit knowledge is employed during controlled processing, it tends to be used when the learner is not under time pressure. Finally, it has been hypothesized that learners' explicit L2 knowledge may be more imprecise and more inaccurate than their implicit knowledge.

Research with a primarily theoretical outlook has further considered metalinguistic knowledge in terms of the categories and relations between categories that are represented explicitly, as well as the nature of the L2 constructions described by explicit categories and relations between categories. Typically, such research has conceptualized metalinguistic knowledge as knowledge of pedagogical grammar rules consisting of explicit descriptions of linguistic phenomena. It has been argued that metalinguistic descriptions may vary along several parameters, including complexity, scope, and reliability (DeKeyser 1994; Hulstijn and de Graaff 1994).

For instance, metalinguistic descriptions may refer to either prototypical or peripheral uses of a particular L2 construction ( $\mathrm{Hu}$ 2002). Moreover, the L2 construction described may itself vary in terms of complexity, perceptual salience, or communicative redundancy (Hulstijn and de Graaff 1994). In view of this multifaceted interaction between the type of explicit description and the type of L2 construction described, it is notoriously difficult to predict which kind of metalinguistic description is likely to be helpful to the L2 learner. Accordingly, positions have shifted somewhat over the years, with earlier work advocating fairly categorically either the teaching of more complex metalinguistic descriptions (Hulstijn and de Graaff 1994), or the teaching of simpler rules (DeKeyser 1994; Green and Hecht 1992).

In recent years, researchers have adopted a more sophisticated line of argument. DeKeyser (2003) has highlighted the fact that the difficulty- 
and hence the potential usefulness - of metalinguistic descriptions is a complex function of a number of variables, including the characteristics of the description itself, the characteristics of the L2 construction being described (see also DeKeyser 2005), and individual learner differences in aptitude.

Indeed, the fact that the relative usefulness of metalinguistic descriptions in L2 learning and performance is affected by a range of variables is to be expected, since language is necessarily learned and used by specific individuals in specific contexts. First and foremost, the role of metalinguistic knowledge in SLA is at least partially dependent upon a learner's current level of L2 proficiency (Butler 2002; Camps 2003; Sorace 1985). Second, a learner's use of metalinguistic knowledge is likely to be subject to situation-specific variation, since both the targeted L2 construction(s) and the task requirements at hand play a part in determining whether and how metalinguistic knowledge is employed (R. Ellis 2005; Hu 2002; Klapper and Rees 2003; Renou 2000). Hence, timed tasks in general and oral task modalities in particular may prevent a learner from allocating sufficient attentional resources to controlled processing involving metalinguistic knowledge, whereas untimed tasks in general and written task modalities in particular may have the opposite effect, possibly encouraging the use of metalinguistic knowledge.

Third, the L1-L2 combination under investigation, paired with the relative typological distance between $\mathrm{L} 1$ and $\mathrm{L} 2$, may have a part to play (Elder and Manwaring 2004). Fourth, length of prior exposure to L2 instruction and the type of instruction experienced have been shown to impact on a learner's level and use of metalinguistic knowledge (Elder et al. 1999; Roehr 2007). Finally, individual differences in cognitive and learning style, strategic preferences, and aptitude may influence a learner's use of metalinguistic knowledge (Collentine 2000; DeKeyser 2003; Roehr 2005).

Most recently, existing work concerned with the role of explicit knowledge in SLA has been complemented by hypotheses about the nature of the representations and processes involved in the use of metalinguistic knowledge. Crucial to the current paper, both empirical findings and theoretical research suggest that explicit and implicit knowledge are separable constructs which are nonetheless engaged in interplay (N. Ellis 1993, 2005; R. Ellis 2005; Segalowitz 2003). In other words, the so-called weakinterface position ${ }^{3}$ allows for the possibility of explicit metalinguistic knowledge contributing indirectly to the acquisition of implicit linguistic knowledge, and vice versa. It has been argued that the two types of knowledge come together during conscious processing (for particularly readable reviews of the complex subject matter of consciousness, see 
Baddeley 1997; Cattell 2006). Moreover, when explicit knowledge is brought to bear on implicit knowledge and vice versa, enduring learning effects may result (N. Ellis and Larsen-Freeman 2006).

The mechanism which is thought to enable conscious processing is called binding. During binding, a number of implicit representations in different modalities are activated simultaneously and integrated into a unified explicit representation that is held in a multimodal code in working memory (Bayne and Chalmers 2003; Dienes and Perner 2003; N. Ellis 2005). We consciously experience this unified representation as a coherent episode. Put differently, the mechanism of binding, explained through the temporally synchronized firing of a number of neurons in different brain regions (Engel 2003), accounts for how implicit representations subserve explicit representations.

With regard to explicit metalinguistic and implicit linguistic processing, it has been proposed that "implicit learning of language occurs during fluent comprehension and production. Explicit learning of language occurs in our conscious efforts to negotiate meaning and construct communication" (N. Ellis 2005: 306). Thus, during fluent language use, the implicit system automatically processes input and produces output, with the individual's conscious self focused on the meaning rather than the form of the utterance. When comprehension or production difficulties arise, however, explicit processes take over. We focus our attention on linguistic form, and we notice patterns; moreover, we become aware of these patterns as unified, coherent representations. Such explicit representations can then be used as pattern recognition units for new stimuli in future usage events. In this way, conscious processing helps consolidate new bindings, which are fed back to the brain regions responsible for implicit processing (N. Ellis 2005).

Steered by the focus of our conscious processing, the repeated simultaneous activation of a range of implicit representations helps consolidate form-meaning associations, often to the extent that implicit learning on subsequent occasions of use becomes possible. Thus, as the various elements constituting a coherent form-meaning association are activated simultaneously during processing, they are bound together more tightly (N. Ellis 2005). Crucially, however, it is not a question of the explicit representation turning into an implicit representation. According to the weak-interface position, it is not the metalinguistic knowledge, e.g., in the form of an explicit description of a linguistic phenomenon, that becomes implicit, but its instantiation, i.e., the sequences of language that the description is used to comprehend or to construct (R. Ellis 2004: 238). ${ }^{4}$

The locus of conscious processing - metaphorically speaking - is working memory. Put differently, explicit knowledge is conceptualized as 
information that is selectively attended to, stored, and processed in working memory. Working memory refers to "the system or mechanism underlying the maintenance of task-relevant information during the performance of a cognitive task" (Shah and Miyake 1999: 1). Thus, working memory allows for the temporary storage and manipulation of information which is being used during online cognitive operations such as language comprehension, learning, and reasoning (Baddeley 2000; Baddeley and Logie 1999). The so-called episodic buffer, a component of working memory, is capable of binding information from a variety of sources and holding such information in a multimodal code. Importantly, working memory is limited in capacity (Just and Carpenter 1992; Miyake and Friedman 1998), i.e., we can only attend to and hence be aware of so much information at any one time.

Clearly, the fact that limited working memory resources constrain explicit processing of language affects L2 and L1 in equal measure. It is well-established that individuals differ in the maximum amount of activation available to them, i.e., that individuals differ in terms of their working memory capacity (e.g., Daneman and Carpenter 1980; Just and Carpenter 1992; Miyake and Shah 1999). Moreover, young children generally have smaller working memory capacity than cognitively mature adolescents and adults. In other words, beyond the issue of individual differences, working memory capacity increases in the course of an individual's development.

In L1 acquisition and use, the emergence of metalinguistic ability is closely associated with the development of literacy skills, that is, another dimension of linguistic competence which requires selective attention to language form (Birdsong 1989; Gombert 1992). As both metalinguistic ability and literacy skills rely on conscious processing drawing on working memory resources, a certain level of cognitive maturity which guarantees sufficient working memory capacity is required; hence, these abilities do not tend to develop until a child is between six and eight years of age.

Metalinguistic processes-whether concerned with L1 or L2 - are analogous to other higher-level mental operations that draw on working memory resources and thus require a certain level of cognitive maturity. Hence, the application of metalinguistic knowledge and the process of analytic reasoning as applied during general problem-solving appear to rely on the same basic mechanisms. Put differently, use of metalinguistic knowledge in language learning and performance can be regarded as analytic reasoning applied to the problem space of language; metalinguistic processing is problem-solving in the linguistic domain (Anderson 1995, 1996; Butler 2002; Hu 2002). 
In L1, a child may raise questions about form-meaning associations ('Why are there two names, orange and tangerine?'), comment on nontarget-like utterances they have overheard (e.g., if another child mispronounces certain words), or objectify language ('Is the a word?'), thus not only demonstrating their ability to monitor language use, but also showing the first signs of what will eventually result in the ability to reason about language (examples adapted from Birdsong 1989: 17; Karmiloff and Karmiloff-Smith 2002: 80). In L2, use of metalinguistic knowledge can likewise be understood in terms of monitoring and reasoning based on hypothesis-testing operations (N. Ellis 2005; Roehr 2005), which are characteristic of a problem-solving approach. Thus, the cognitively mature L2 learner may deliberately analyze input in an attempt to comprehend an utterance ('What is the subject and what is the object in this sentence?'), or creatively construct output that is monitored for formal accuracy ('If I use a compound tense in this German clause, the first verb needs to be in second position and the second verb in final position.')

To summarize this section, available empirical evidence about the role of explicit knowledge in language learning and use bears out the theoretically motivated expectation that metalinguistic knowledge can have both benefits and limitations. Whilst the facilitative effect of focused attention in the sense of stimulus detection is all but undisputed, determining the impact of higher levels of learner awareness and more explicit types of learner knowledge which go beyond focused attention in the sense of stimulus detection is less straightforward. On the one hand, L2 proficiency and metalinguistic knowledge have been found to correlate positively and significantly. Moreover, use of metalinguistic knowledge is typically associated with performance patterns characterized by consistency and systematicity. On the other hand, use of metalinguistic knowledge is by no means a guarantee of successful performance, and higher levels of learner awareness that reach beyond noticing may be unnecessary or possibly even unhelpful in certain situations.

In the area of theory, a recent position includes the proposal that explicit and implicit knowledge are separate and distinct, but can interact. Hence, explicit knowledge about language may contribute indirectly to the development of implicit knowledge of language, and vice versa. As explicit and implicit knowledge interface during conscious processing, and as such processing is subject to working memory constraints, use of metalinguistic knowledge in language learning and performance is likely to have not only benefits, but also certain limitations. On the one hand, conscious processing involving the higher-level mental faculty of analytic reasoning allows the cognitively mature individual to apply a problemsolving approach to language learning. On the other hand, conscious 
processing is constrained by limited working memory capacity and thus only permits the consideration of a restricted amount of information at any one time.

Finally, existing research acknowledges that the relative usefulness of metalinguistic knowledge can be expected to depend on a range of learner-internal and learner-external variables, including task modalities, the learner's level of L2 proficiency, their language learning experience, their cognitive abilities, and their stylistic orientation.

Whilst it is important to bear in mind that all these factors will differentially affect the role of metalinguistic knowledge in language learning and performance (see Section 6 below), it is argued here that, ceteris paribus and over and above these factors, another, more fundamental variable which goes beyond specific usage situations and individual learner differences is worthy of consideration: The contrasting category structures of implicit linguistic knowledge representations on the one hand and explicit metalinguistic knowledge representations on the other hand as well as the different modes of implicit, associative processing and explicit, rulebased processing constitute the basic cognitive conditions in which language learning and performance take place. If taken into account, these phenomena not only help explain existing findings about the apparently ambivalent role of metalinguistic knowledge in L2 learning and use, but also permit us to formulate specific empirical predictions that can guide future research.

\section{The representation and processing of implicit linguistic knowledge and explicit metalinguistic knowledge}

As linguistic and metalinguistic knowledge pertain to the same cognitive domain - language - they can be expected to share certain characteristics. Specifically, it appears that linguistic constructions and metalinguistic descriptions vary along the same parameters, namely, specificity and complexity. The usage-based model assumes that linguistic constructions can be more or less specific as well as more or less complex (see Figure 1 above). By the same token, empirical evidence suggests that L2 learners' metalinguistic knowledge can be more or less specific and more or less complex (e.g., Roehr 2005, 2006; Rosa and O’Neill 1999).

For the purpose of illustration, one might imagine the case of an educated L1 English-speaking adult learner of L2 German and consider their metalinguistic knowledge which has mostly been derived from encounters with pedagogical grammar in the classroom and in textbooks. ${ }^{5}$ Thus, a metalinguistic description which this learner is aware of can refer to specific instances, e.g., 'German hin expresses movement away from the 
speaker, while her expresses movement towards the speaker'. Alternatively, it can be entirely schematic and therefore involve no specific exemplars at all, e.g., 'a subordinating conjunction sends the finite verb to the end of the clause'. Both of these examples are additionally complex, i.e., they state relations between categories, and they can be broken down into their constituent parts and therefore require several mental manipulations during processing (DeKeyser 2003; Stankov 2003). However, a metalinguistic description can also be minimal, e.g., 'noun'. Various combinations of different levels of specificity and complexity seem possible - with the exception of both minimal and specific.

In fact, the joint characteristics of minimal and specific appear to be unique to lexical items, that is, linguistic constructions. By contrast, even entirely specific metalinguistic descriptions containing no schematic categories such as 'German $e i$ is pronounced like English $i$ ' or 'English desk means Schreibtisch in German' involve a relation between two specific instances and can therefore still be broken down into their constituent parts. By the same token, a minimal metalinguistic description such as 'noun', which cannot be broken down any further, is schematic rather than specific. Put differently, as soon as implicit linguistic knowledge is made explicit, i.e., when a metalinguistic knowledge representation is created (no matter by whom, whether an L2 learner, an applied linguist, or any other language user), it seems to take the form of either a schematic description ('noun'), or a proposition involving at least two categories and a relation between them.

It should be pointed out that this circumstance does not exclude statements about the lexicon from the realm of metalinguistic description and representation; quite to the contrary, semantic knowledge is perhaps the most obvious area of explicit knowledge about language, since it typically encompasses not only L2 metalinguistic knowledge, but also L1 metalinguistic knowledge. Indeed, we can glean metalinguistic knowledge about lexical items from any monolingual or bilingual dictionary. However, it is crucial to note that, when made explicit, semantic knowledge incorporates at least two categories and a relation between them, as exemplified by dictionary definitions of any description. Even the briefest listing of a synonym without further explanatory comment amounts to stating a relation between two categories ('X means Y'). Hence, one can argue that implicit knowledge of the meaning, function, and appropriate usage contexts of minimal and specific linguistic constructions such as lexical items is distinguishable from explicit knowledge about the meaning, function, and appropriate usage contexts of these constructions. This claim applies not only to implicit knowledge of and explicit knowledge about the lexicon, but also to all other areas of language. 
Whilst metalinguistic knowledge is comparable with linguistic constructions in terms of the parameters of complexity and specificity, explicit metalinguistic knowledge differs qualitatively from implicit linguistic knowledge in the crucial respect of categorization, that is, one of the key cognitive phenomena underlying conceptual as well as linguistic representation and processing. As outlined in Section 3 above, the usagebased model assumes that cognitive categories, whether conceptual or linguistic, are flexible and context-dependent, sensitive to prototype effects, and have fuzzy boundaries.

By contrast, metalinguistic knowledge appears to be characterized by stable, discrete, and context-independent categories with clear-cut boundaries. Put differently, metalinguistic knowledge relies on what has alternately been labelled Aristotelian, categorical, classical, or scientific categorization (Anderson 2005; Bod et al. 2003; Taylor 2003; Ungerer and Schmid 1996). For instance, the metalinguistic category 'subordinating conjunction' is stable and clearly defined; in the case of German, it is instantiated by a certain number of exemplars, such as weil ('because'), da ('as'), wenn ('if, when'), etc. Although some instantiations occur more frequently than others, there are no better or worse category members; all subordinating conjunctions have equal status and are equally valid exemplars, regardless of context.

By the same token, the linguistic construction [NOUN] and the metalinguistic description 'noun' can be contrasted. As all linguistic constructions are form-meaning pairings, the linguistic construction [NOUN] is not devoid of semantic content. Even though it has no specific phonological instantiation, it has been abstracted over a large number of exemplars occurring in actual usage events (as exemplified in more detail for the English ditransitive construction in Section 3 above); accordingly, the linguistic construction [NOUN] is strongly associated with the semantics of its most frequent instantiations, such as lexical items denoting entities in the real world. Consequently, in the average user of English, the highly frequent and prototypical constructions man, woman and house can be expected to be more strongly associated with the schema [NOUN] than the relatively rare constructions rumination and oxymoron, or the dual-class words brush and kiss, for instance. Likewise, in the average user of German, Fühlen ('the sensing/feeling') is likely to be a relatively marginal instantiation of the category [NOUN], compared with the more common instantiation Gefühl ('sensation/feeling'). The more marginal status of Fühlen can be attributed to the relative rarity of its nominal usage as well as its homophone fühlen ('sense/feel'), a prototypical verb. Thus, by dint of its association with various instantiations, their respective conceptual referents, and their usage contexts, the linguistic schema 
[NOUN] exhibits a category structure which is characterized by flexibility and context-dependency, and which takes into account prototype effects.

The metalinguistic description 'noun', on the other hand, relies on Aristotelian categorization. It may be defined by means of a discrete statement, e.g., as "a word (...) which can be used with an article" (Swan 1995: xxv) or "a content word that can be used to refer to a person, place, thing, quality, or action". ${ }^{6}$ Metalinguistic categorization is based on clear yes/no distinctions; frequency distributions or contextual information are not taken into account, and prototype effects are filtered out. Thus, in metalinguistic terms, the constructions man, woman, house, rumination, oxymoron, brush, kiss, Fühlen, and Gefühl all have equal status as members of the Aristotelian category 'noun'.

Of course, use of Aristotelian categorization does not mean that we as language users are unaware of the potential shortcomings of such an approach. This awareness is also acknowledged in L2 instruction which draws on metalinguistic descriptions. Most L2 learners will be able to think of examples of pedagogical grammar rules that are qualified by frequency adverbs such as usually, in general, etc. Most L2 learners will likewise be familiar with statements about specific usage contexts as well as lists of exceptions to a rule that apparently have to be learned by rote. Finally, the realm of metalinguistic descriptions is not immune to prototype effects. For instance, descriptions of prototypical functions of a certain L2 form will occur more often than descriptions of less prototypical functions of the same form and will thus be more familiar to learners (Hu 2002). However, it is argued here that these prototype effects only concern the presentation and/or our perception of metalinguistic descriptions; they do not seem to have any bearing on the internal category structure of explicit knowledge representations or the processing mechanisms operating on these representations, as explicated in the following.

As a matter of fact, in order to be of use, metalinguistic knowledge requires conditions of stability and discreteness; otherwise, it would be of little practical value (see also Swan 1994). For metalinguistic knowledge to be informative, the user needs to decide categorically whether a specific linguistic construction is to be classified as a noun or not, otherwise a metalinguistic description such as 'the verb needs to agree in number with the preceding noun or pronoun' cannot be implemented. By the same token, the user needs to decide categorically whether a linguistic construction is a subordinate conjunction or not, otherwise a metalinguistic description such as 'in German, the finite verb appears at the end of a subordinate clause' cannot be employed. 
To exemplify further, the metalinguistic description 'in English reported speech, the main verb of the sentence changes to the past tense when it is in the present tense in direct speech' applies in equal measure to all English utterances, unless it is qualified by further statements about specific contexts, e.g., 'if something that is still true at the time of speaking is being reported, the main verb may remain in the present tense'. Further propositions are required to make explicit the formal and functional criteria of introducing reported speech by means of different verbs such as say and tell, to describe the formal and functional aspects of reported questions, and so forth (example adapted from Murphy 1994). No matter how many statements are formulated, though, the user needs to be able to clearly assign category membership in each case in order to be able to apply the metalinguistic description, represented as metalinguistic knowledge, to a concrete linguistic construction. If we cannot decide categorically if something is a main verb, if something is direct speech, etc., we cannot bring to bear our explicit knowledge.

As a final example, consider a general, dictionary-style metalinguistic description pertaining to the constructions desk and Schreibtisch ('desk'), which is again necessarily stable and discrete. The statement that 'English desk means Schreibtisch in German' is posited as a context-independent proposition which does not take into account prototypicality or usage situations. In order to achieve a finer descriptive grain, additional propositions need to be formulated, e.g., 'in the context of English check-in desk, the word Check-in-Schalter needs to be used in German'. Conversely, the implicit linguistic knowledge of a proficient user of both English and German would accurately reflect the frequency distributions of the constructions desk, Schreibtisch, and Schalter in connection with the relevant referential meanings and suitable pragmatic contexts in which these constructions tend to appear.

The same principle applies to the internal structure of all metalinguistic categories and propositions about relations between categories that make up metalinguistic descriptions, regardless of whether these refer to lexicosemantic, morphosyntactic, phonological, or pragmatic phenomena: Aristotelian categories are needed to allow for the effective deployment of metalinguistic knowledge. To reiterate, if we cannot take clear-cut decisions about category membership, our metalinguistic knowledge is of litthe practical value in concrete usage situations.

The contrasting category structures of implicit linguistic and explicit metalinguistic representations can be expected to affect the processing mechanisms which operate on these representations during language learning and use. Indeed, implicit and explicit mental operations involving natural language appear to be analogous with what is respectively 
termed similarity-based and rule-based processing in the field of cognitive psychology.

Similarity-based and rule-based processing have been studied in relation to categorization, reasoning, and artificial language learning, and experimental evidence for a qualitative distinction between the two processes is quite robust, though not uncontroversial. In accordance with the weak-interface position adopted in the current paper (see Section 4 above), I am in agreement with researchers who not only regard rulebased and similarity-based processing as separable and distinct, but also argue that the defining property of rule-based processing is its conscious nature (Cleeremans and Destrebecqz 2005; Hampton 2005; Smith 2005). As mentioned previously, conscious awareness "occurs" in working memory, a limited-capacity resource; as rule-based processes require executive attention and effort, they may exceed an individual's working memory capacity (Ashby and Casale 2005; Bailey 2005; Reber 2005).

Empirical evidence indicates that rule-based processing is characterized by compositionality, productivity, systematicity, commitment, and a drive for consistency (Diesendruck 2005; Pothos 2005; Sloman 2005). A set of operations is compositional when more complex representations can be built out of simpler components without a change in the meaning of the components. Productivity means that, in principle, there is no limit to the number of such new representations. An operation is systematic when it applies in the same way to a whole class of objects (Pothos 2005). Rulebased processing entails commitment to specific kinds of information, while contextual variations are neglected (Diesendruck 2005). The reason for this is that rule-based operations involve only a small subset of an object's properties which are selected for processing, while all other object dimensions are suppressed (Markman et al. 2005; Pothos 2005). A strict match between an object's properties and the properties specified in the rule has to be achieved for rule-based processing to apply. Because of this, rule-based judgements are more consistent and more stable than similarity-based judgements (Diesendruck 2005; Pothos 2005). It should be immediately apparent that all these properties of rule-based processing are in keeping with the characteristics of Aristotelian category structure detailed and exemplified above in relation to metalinguistic knowledge, i.e., stability, discreteness, lack of flexibility, as well as selective and categorical decision-making.

The characteristics of rule-based processing can be contrasted with the characteristics of similarity-based processing. The latter involves a large number of an object's properties, which only need to be partially matched with the properties of existing representations to allow for successful categorization (Pothos 2005). Moreover, and contrary to rule-based 
processing, similarity-based processing is flexible, dynamic, open, and susceptible to contextual variation (Diesendruck 2005; Markman et al. 2005). Again, it should be apparent that the attributes of similarity-based processing identified in the field of cognitive psychology are fully consonant with the characteristics of implicit linguistic categories assumed in the usage-based model.

It is now possible to consider the empirical findings about the role of metalinguistic knowledge in language learning (see Section 4 above) in light of the proposed conceptualization of explicit metalinguistic representations and processes as opposed to implicit linguistic representations and processes. First, I have argued that linguistic and metalinguistic knowledge pertain to the same cognitive domain (language) and vary along the same parameters (specificity and complexity). These circumstances are consistent with the empirical finding that the two types of knowledge are positively correlated in L2 learners. At the same time, it is of course necessary to bear in mind that, considered on their own, correlations do not allow for direct conclusions to be drawn about causeeffect relationships, or indeed the directionality of such relationships.

Second, I have suggested that linguistic and metalinguistic knowledge differ qualitatively in terms of their internal category structure, with implicitly represented categories characterized by flexibility, fuzziness, and context-dependency, and explicitly represented categories showing the contrasting attributes of Aristotelian structure. This proposal is compatible with the existing claim that the two types of knowledge are separate and distinguishable constructs.

Third, research in cognitive psychology has revealed that rule-based processes, i.e., processes which operate on explicit knowledge representations, are characterized by compositionality, productivity, systematicity, commitment, and a drive for consistency. These characteristics are consonant with the empirical finding that use of metalinguistic knowledge is associated with consistent, systematic, and often successful L2 performance.

Fourth, rule-based processes are associated with stability and definite commitment to selected information, while flexibility and attention to contextual variation are absent. Furthermore, as rule-based processes require both attentional resources and effort, they are constrained by an individual's working memory capacity. These circumstances are in keeping with the empirical finding that use of metalinguistic knowledge does not guarantee successful L2 performance and may even be unhelpful in certain situations. Put differently, rule-based processes operating on Aristotelian categories may not only exceed an individual's working memory resources in a given situation, but may also fail to capture the 
intricacies of certain linguistic constructions in the first place, as exemplified below. ${ }^{7}$

In sum, it appears that the proposed conceptualization of explicit metalinguistic representations and rule-based processes can account for the benefits as well as the limitations of knowledge based on Aristotelian category structure. Such knowledge is at its best when it pertains to highly frequent and entirely systematic patterns whose usage is largely independent of context and may be described in terms of one or a few relations between categories. 'In English, an $-s$ needs to be added to present tense verbs in the third person' is an example of a metalinguistic description instantiating metalinguistic knowledge of this kind. Conversely, metalinguistic knowledge is less useful, or perhaps even useless, when less frequent, more item-based constructions exhibiting complicated formmeaning relations need to be captured, since the required number of categories and propositions specifying relations between categories grows rapidly with every specific usage context that diverges from the regular pattern.

To exemplify, our implicit representations of the linguistic constructions desk and Schreibtisch ('desk') include a wealth of information about appropriate pragmatic usage contexts of the linguistic forms based on cultural models relating to the meanings they symbolize. Accordingly, the implicit linguistic representations of a proficient user of English and German would include information about the suitability of the construction desk to describe an item of furniture commonly found in an office, as well as the place where you check in at an airport or see a bank clerk to open an account. Furthermore, the proficient user would hold information about the suitability of the construction Schreibtisch in the former scenario but not in the latter.

At the implicit level, this probabilistic information is represented in a vast network of associations subject to parallel distributed processing, i.e., non-conscious operations that are unaffected by the constraints of working memory and the cumbersome propositional nature of explicit knowledge representations and processes. By contrast, the Aristotelian categories and relations of the relevant metalinguistic description require the formulation of a set of independent propositions that specify different usage situations, such as 'English desk is Schreibtisch in German'. 'However, if you want to say English desk in German and if the expression is used in the context of an airport or a bank, Schalter needs to be used', and so forth.

At the level of more schematic categories, the implicit linguistic knowledge of a proficient user of English and German would include not only the schema [CO-ORDINATING CONJUNCTION], but likewise instantiations of 


\section{K. Roehr}

this schema, all of which are associated with a wealth of linguistic and conceptual context information. Accordingly, the fact that the German constructions aber, jedoch, allein and sondern may all be translated as English but would be complemented not only by information about the high frequency of aber, but also by knowledge of the specific syntactic properties of jedoch, the literary or archaic connotations of allein, the tendency of sondern to be used in contradicting a preceding negative, etc. However, the metalinguistic descriptions formulated in the previous sentence clearly show that, when made explicit, this information needs to be stated in terms of additional independent propositions based on stable and discrete categories.

This potentially explosive growth of propositions that would be required to make explicit representations applicable in different contexts has two detrimental consequences. First, it increases working memory load and thus renders metalinguistic knowledge proportionally more burdensome to process; and, second, it becomes less widely applicable. These potential drawbacks of explicit, rule-based processes apply in equal measure to the use of metalinguistic knowledge, i.e., reasoning about language, and reasoning in other cognitive domains: 'If there is white-grey smoke coming out of the kitchen oven where I have had fish cooking for the last three hours, then there is a fire' (example adapted from Pothos 2005: 8) is obviously both harder to process and less useful than 'if there is smoke, then there is fire'. Unfortunately, the complexity, flexibility, and context-dependency of natural language means that general (and truthful) metalinguistic descriptions equivalent to the latter statement are inevitably rather rare.

\section{Empirical predictions}

In the preceding section, I have argued that the distinct category structures and processes which characterize explicit and implicit knowledge are consonant with existing findings in the area of SLA. Naturally, a retrospective explanatory account can only take us so far. However, the theoretical proposals I have put forward offer us further and arguably more important insights: They allow for the formulation of empirically testable predictions with regard to the role of metalinguistic knowledge in L2 learning. In what follows, five specific hypotheses which are intended to inform future research are presented.

(1) Linguistic constructions which are captured relatively easily by Aristotelian categories and relations between such categories will be easier to acquire explicitly than linguistic constructions which are not captured easily by Aristotelian categories and relations between such categories. 
Specifically, linguistic constructions which show comparatively systematic, stable, and context-independent usage patterns should be more amenable to explicit teaching and learning than linguistic constructions which do not show these usage patterns.

There is as yet very little existing research which has investigated the potential amenability of specific linguistic constructions to explicit L2 instruction drawing on metalinguistic descriptions, even though theoretically motivated predictions about the potential difficulties of simple versus complex metalinguistic rules were put forward more than a decade ago (e.g., DeKeyser 1994; Hulstijn and de Graaff 1994). Recent empirical findings suggest that L2 form-function mappings which can be described metalinguistically in conceptually simple terms and which refer to systematic usage patterns appear to pose the least explicit learning difficulty ( $R$. Ellis 2006; Roehr and Gánem 2007) and may therefore be particularly suitable for explicit teaching and learning. By contrast, L2 form-function mappings with less systematic usage patterns which require conceptually complex metalinguistic descriptions should pose greater explicit learning difficulty. In view of the small number of studies that have been conducted so far, further investigation of Hypothesis 1 is clearly required.

(2) Use of metalinguistic knowledge will differentially affect the fluency, accuracy, and complexity of L2 performance. Specifically, fluency may decrease, while accuracy and complexity may increase.

Existing research has shown that L2 learners' metalinguistic knowledge correlates positively with L2 proficiency - provided that the latter is operationalized by means of written rather than oral measures (e.g., Alderson et al. 1997; Elder et al. 1999; Renou 2000). Given that the use of explicit knowledge requires controlled processing which is by definition slow and effortful compared with automatic, implicit operations, this finding is perfectly compatible with previous theoretical argumentation. However, whilst L2 proficiency has typically been operationalized via discrete-item tests of structural and lexical competence and/or via the four skills of reading, writing, speaking, and listening, no study to date has investigated learners' use of metalinguistic knowledge in relation to the SLA-specific developmental measures of fluency, accuracy, and complexity (R. Ellis and Barkhuizen 2005; Larsen-Freeman 2006; Skehan 1998) which cut across both oral and written performance.

In view of the fact that explicit, rule-based processing drawing on representations with Aristotelian category structure is subject to working memory constraints and thus relies on the selective allocation of attentional resources, one would expect that increased accuracy, for instance, can only be achieved at the expense of decreased complexity and fluency. Likewise, increased complexity can only be achieved at the expense of 
decreased accuracy and fluency, whereas increased fluency is unlikely to be achieved at all in association with high use of metalinguistic knowledge. Averaged across a group of learners, these predicted patterns should hold for both oral and written performance, although trade-off effects can be expected to be stronger in the case of oral performance, since the time pressures of online processing inevitably place even higher demands on working memory. To my knowledge, none of the performance patterns hypothesized here have been subjected to empirical enquiry yet.

(3) Use of metalinguistic knowledge will be related to cognitively based individual learner differences. Specifically, a learner's cognitive and learning style, language learning aptitude, and working memory capacity are likely to differentially affect their use of metalinguistic knowledge in L2 performance.

I have argued that metalinguistic knowledge representations exhibit Aristotelian category structure and that rule-based processing mechanisms operate on these representations. As mentioned previously, rulebased processing mechanisms are characteristic of analytic reasoning more generally, so that use of metalinguistic knowledge can be regarded as problem-solving in the linguistic domain. Accordingly, individuals with an analytic stylistic orientation and large working memory capacity should be particularly adept at using metalinguistic knowledge.

While existing research has occasionally speculated on some of these issues (e.g., Collentine 2000; DeKeyser 2003), no study to date has probed the relationship between L2 learners' metalinguistic knowledge and their stylistic preferences (for recent work on cognitive and learning style in SLA more generally, see, for instance Ehrman and Leaver 2003; Reid 1998). As far as I am aware, only one study to date has directly investigated the interplay of L2 learners' metalinguistic knowledge, their language learning aptitude, and their working memory capacity (Roehr and Gánem 2007). Results indicate that learners' level of metalinguistic knowledge and their working memory capacity are unrelated, but that analytic components of language learning aptitude, i.e., components whose operationalization incorporates no purely memory-based or purely auditory elements, were positively correlated with learners' level of metalinguistic knowledge $(r=0.42)$. In view of the shortage of available evidence, further research into the relationship between metalinguistic knowledge and cognitively based individual difference variables is needed.

(4) Use of metalinguistic knowledge and cognitively based individual differences will be related to learners' affective responses. Specifically, individuals with an analytic disposition who are likely to benefit from explicit learning and teaching drawing on metalinguistic knowledge will experience feelings of greater self-efficacy and will thus develop positive 
attitudes towards their L2 learning situation. By contrast, individuals with a non-analytic disposition who are likely to benefit less from explicit learning and teaching drawing on metalinguistic knowledge will experience greater anxiety and will thus develop negative attitudes towards their L2 learning situation.

To my knowledge, there is as yet no published research that has put this prediction to the test (but see Roehr 2005 for some preliminary analyses based on a small number of cases; for work on the interaction of affect and cognition more generally, see, for instance, Schumann 1998, 2004; Stevick 1999). In view of Hypothesis 1 above, it is plausible to hypothesize that metalinguistic descriptions which pertain to linguistic constructions characterized by systematic and relatively context-independent usage patterns may be facilitative for any L2 learner, regardless of cognitively based individual differences. Such metalinguistic descriptions may focus a learner's attention on aspects of the L2 input that might otherwise be ignored, thus leading to noticing, i.e., conscious processing just above the threshold of awareness, and all its associated benefits.

If, on the other hand, metalinguistic descriptions pertaining to linguistic constructions that pose more substantial explicit learning difficulty according to Hypothesis 1 are used, cognitively based individual learner differences should begin to matter. An analytically oriented individual may continue to benefit by moving beyond noticing towards understanding, thus relying on conscious processing at a high level of awareness (Schmidt 1990, 1993, 2001). The achievement of understanding is likely to result in positive affective responses such as feelings of greater self-efficacy and enhanced self-confidence. A positive attitude towards the L2 learning situation may result, which would in turn encourage the learner to deliberately seek further exposure to the L2. In a learner with a different stylistic orientation, however, this upward dynamic could well be replaced by a downward spiral of failure to understand, feelings of anxiety and loss of control, a negative attitude towards the L2 learning situation, and, in the worst-case scenario, the eventual abandonment of L2 study. This hypothesized interaction of cognitive and affective variables can and should be put to the test.

(5) Use of metalinguistic knowledge in L2 learning will be related to L1 metalinguistic ability. Specifically, individuals who show strong metalinguistic ability and literacy skills in L1 development are likely to exhibit high levels of metalinguistic knowledge in L2.

With regard to metalinguistic knowledge in adult learners, the link between L1 and L2 skills has not been widely explored. Some studies have incorporated measures of L1 metalinguistic knowledge alongside tests of L2 metalinguistic knowledge (e.g., Alderson et al. 1997), or acknowledged 
the association between metalinguistic and literacy skills (e.g., Kemp 2001). Furthermore, existing research has emphasized the link between L1 ability and aptitude for L2 learning (e.g., Sparks and Ganschow 2001), or highlighted the fact that multilingual individuals generally show greater metalinguistic awareness (e.g., Jessner 1999, 2006). Yet, I am not aware of any published study of cognitively mature learners which has directly focused on the relationship between L1 and L2 competence on the one hand and L1 and L2 metalinguistic knowledge on the other hand. If Hypotheses 3 and 4 are borne out, the patterns of interplay between individual difference variables and metalinguistic knowledge can be expected to be similar in both L1 and L2.

\section{Conclusion}

In this paper, I have put forward a theoretically motivated and empirically grounded conceptualization of the construct of metalinguistic knowledge, or explicit knowledge about language, with specific reference to L2 learning. I have argued that explicit metalinguistic and implicit linguistic knowledge vary along the same parameters, specificity and complexity, but that they differ qualitatively in terms of their internal category structure and, accordingly, the processing mechanisms that operate on their representation in the human mind. In consonance with assumptions made in the usage-based approach to language, implicit knowledge is characterized by flexible and context-dependent categories with fuzzy boundaries. By contrast, explicit knowledge is represented in terms of Aristotelian categories with a stable, discrete, and context-independent structure.

In accordance with research in cognitive psychology, implicit knowledge is subject to similarity-based processing which is characterized by dynamicity, flexibility, and context-dependency. Conversely, explicit knowledge is subject to rule-based processing which is both conscious and controlled. Such processing is constrained by the capacity limits of working memory; it requires effort, selective attention, and commitment. Rule-based processing is further characterized by stability and consistency-properties that are achieved at the cost of flexibility and consideration of contextual and frequency information. Rule-based processing underlies analytic reasoning, whether in the linguistic or any other cognitive domain. Hence, use of metalinguistic knowledge can be understood as problem-solving applied to language.

The proposed attributes of implicit linguistic and explicit metalinguistic category structures and processes have been considered in relation to available research in the field of SLA, and a post-hoc account that is 
consistent with both the benefits and the limitations of metalinguistic knowledge as identified in existing research has been provided. Arising from the theoretical proposals put forward in the present paper, I have further formulated five specific predictions which, if confirmed, would identify the conditions under which metalinguistic knowledge is likely to be useful to the L2 learner. These predictions constitute empirically testable hypotheses which, it is hoped, will be addressed in future research.

\section{Received 7 August 2006}

University of Essex, UK

Revision received 16 May 2007

\section{Notes}

* I would like to thank Martin Atkinson, Bob Borsley, Ewa Dabrowska, and two anonymous reviewers for their helpful and constructive comments. I am also grateful to Sonja Eisenbeiss, Roger Hawkins, and Max Roberts for reading an earlier version of this paper. Address for correspondence: Karen Roehr, Department of Language \& Linguistics, University of Essex, Wivenhoe Park, Colchester CO4 3SQ, UK; email: $\langle$ kroehr@essex.ac.uk〉.

1. The following notation conventions are used: Schematic categories are shown in small capitals with square brackets, e.g., [BIRD]. Exemplars of conceptual categories are shown in small capitals, e.g., ROBIN. Specific linguistic constructions are shown in italics, e.g., bachelor, unrepentant, etc. Metalinguistic descriptions are shown in single inverted commas, e.g., ' $d a$ sends the finite verb to the end of the clause'.

2. Langacker's (1991) terminology is employed throughout this article. Croft (2001) uses the terms "atomic" and "substantive" instead of "minimal" and "specific", respectively.

3. The weak-interface position can be contrasted with the non-interface position and the strong-interface position. The non-interface position contends not only that explicit and implicit knowledge are separate and distinct constructs, but also that they cannot engage in interplay (Krashen 1981, 1985; Paradis 2004). The strong-interface position maintains that explicit and implicit knowledge interact directly, and that explicit knowledge may be converted into implicit knowledge, e.g., through prolonged practice (DeKeyser 1994; Johnson 1996; McLaughlin 1995). A review of these various positions can be found in R. Ellis (2005).

4. Current research into the interface between explicit and implicit knowledge does not yet offer any highly precise descriptions of the links between the level of the mind and the level of the brain. Likewise, researchers' understanding of the notion of consciousness is still incomplete. Therefore, what I present here are hypotheses that are compatible with existing empirical findings. While recognizing that further research is required, I regard these hypotheses both as sufficiently plausible to be given serious consideration and as sufficiently detailed to be incorporated into a coherent line of argument.

5. As mentioned previously, for the current discussion it does not matter whether an individual's metalinguistic knowledge has been derived internally or assimilated from external sources.

6. URL: 〈http://wordnet.princeton.edu/perl/webwn〉, retrieved 16 April 2007, based on a keyword search for "noun".

7. This circumstance is consistent with the proposal that explicit knowledge about language may be more inaccurate and more imprecise than implicit knowledge (R. Ellis 
2004, 2005, 2006). While, at first glance, this hypothesis seems to be incompatible with the attributes of rule-based processing, it fits into the picture if the limitations of metalinguistic knowledge based on representations with Aristotelian category structure are taken into consideration.

\section{References}

Abbot-Smith, Kirsten and Michael Tomasello

2006 Exemplar-learning and schematization in a usage-based account of syntactic acquisition. The Linguistic Review 23 (3), 275-290.

Achard, Michel, and Susanne Niemeier (eds.)

2004 Cognitive Linguistics, Second Language Acquisition, and Foreign Language Teaching. Berlin: Mouton de Gruyter.

Alderson, J. Charles, Caroline Clapham, and David Steel

1997 Metalinguistic knowledge, language aptitude and language proficiency. Language Teaching Research 1, 93-121.

1995 Learning and Memory: An Integrated Approach. New York, NY: John Wiley and Sons.

Anderson, John R.

1996 The Architecture of Cognition. Mahwah, NJ: Erlbaum.

2005 Cognitive Psychology and its Implications (6th ed.). New York, NY: Worth Publishers.

Ashby, F. Gregory and Michael B. Casale

2005 Empirical dissociations between rule-based and similarity-based categorization. Behavioral and Brain Sciences 28 (1), 15-16.

Baddeley, Alan D.

1997 Human Memory: Theory and Practice. Hove: Psychology Press.

2000 The episodic buffer: A new component of working memory? Trends in Cognitive Sciences 4 (11), 417-423.

Baddeley, Alan D. and Robert H. Logie

1999 Working memory: The multiple-component model. In Miyake, Akira and Priti Shah (eds.), Models of Working Memory: Mechanisms of Active Maintenance and Executive Control. Cambridge: Cambridge University Press, $28-61$.

Bailey, Todd M.

2005 Rules work on one representation; similarity compares two representations. Behavioral and Brain Sciences 28 (1), 16.

Bates, Elizabeth A. and Judith C. Goodman

2001 On the inseparability of grammar and the lexicon: Evidence from acquisition. In Tomasello, Michael and Elizabeth A. Bates (eds.), Language Development. Malden, MA: Blackwell, 134-162.

Bayne, Tim and David J. Chalmers

2003 What is the unity of consciousness? In Cleeremans, Axel (ed.), The Unity of Consciousness: Binding, Integration, and Dissociation. Oxford: Oxford University Press, 23-58.

Bialystok, Ellen

1979 Explicit and implicit judgements of L2 grammaticality. Language Learning 29 (1), 81-103.

Birdsong, David

1989 Metalinguistic Performance and Interlinguistic Competence. Berlin: Springer. 
Bod, Rens, Jennifer Hay, and Stefanie Jannedy

2003 Introduction. In Bod, Rens, Jennifer Hay, and Stefanie Jannedy (eds.), Probabilistic Linguistics. Cambridge, MA: MIT Press, 1-10.

Boers, Frank and Seth Lindstromberg

2006 Cognitive linguistic applications in second and foreign language instruction:

Rationale, proposals, and evaluation. In Kristiansen, Gitte, Michel Achard,

René Dirven, and Francisco J. Ruiz de Mendoza Ibánez (eds.), Cognitive

Linguistics: Current Applications and Future Perspectives. Berlin: Mouton

Butler, Yuko Goto de Gruyter, 303-355.

2002 Second language learners' theories on the use of English articles: An analysis of the metalinguistic knowledge used by Japanese students in acquiring the English article system. Studies in Second Language Acquisition 24 (3), 451-480.

Bybee, Joan L. and James L. McClelland

2005 Alternatives to the combinatorial paradigm of linguistic theory based on domain general principles of human cognition. The Linguistic Review 22 (2-4), $381-410$.

Camps, Joaquim

2003 Concurrent and retrospective verbal reports as tools to better understand the role of attention in second language tasks. International Journal of Applied Linguistics 13 (2), 201-221.

Cattell, Ray

2006 An Introduction to Mind, Consciousness and Language. London: Continuum.

Chalker, Sylvia

1994 Pedagogical grammar: Principles and problems. In Bygate, Martin, Alan

Tonkyn, and Eddie Williams (eds.), Grammar and the Language Teacher.

New York, NY: Prentice Hall, 31-44.

Cleeremans, Axel and Arnaud Destrebecqz

2005 Real rules are conscious. Behavioral and Brain Sciences 28 (1), 19-20.

Collentine, Joseph

2000 Insights into the construction of grammatical knowledge provided by userbehavior tracking technologies. Language Learning and Technology 3 (2), $44-57$.

Croft, William

2001 Radical Construction Grammar: Syntactic Theory in Typological Perspective. Oxford: Oxford University Press.

Daneman, Meredyth and Patricia A. Carpenter

1980 Individual differences in working memory and reading. Journal of Verbal Learning and Verbal Behavior 19, 450-466.

DeKeyser, Robert M.

1994 How implicit can adult second language learning be? AILA Review 11, 83-96.

2003 Implicit and explicit learning. In Doughty, Catherine J. and Michael H.

Long (eds.), The Handbook of Second Language Acquisition. Malden, MA: Blackwell, 313-348.

2005 What makes learning second-language grammar difficult? A review of issues. Language Learning 55(s1), 1-25.

Dienes, Zoltán and Josef Perner

2003 Unifying consciousness with explicit knowledge. In Cleeremans, Axel (ed.), The Unity of Consciousness: Binding, Integration, and Dissociation. Oxford: Oxford University Press, 214-232. 
Diesendruck, Gil

2005 "Commitment" distinguishes between rules and similarity: A developmental perspective. Behavioral and Brain Sciences 28 (1), 21-22.

Dirven, René

$1990 \quad$ Pedagogical grammar. Language Teaching 23 (1), 1-18.

Dirven, René and Marjolijn Verspoor

2004 Cognitive Exploration of Language and Linguistics (2nd ed.). Amsterdam: John Benjamins.

Doughty, Catherine J.

1991 Second language instruction does make a difference: Evidence from an empirical study of SL relativization. Studies in Second Language Acquisition 13, 431-469.

2003 Instructed SLA: Constraints, compensation, and enhancement. In Doughty, Catherine J. and Michael H. Long (eds.), The Handbook of Second Language Acquisition. Malden, MA: Blackwell, 256-310.

Ehrman, Madeline E. and Betty Lou Leaver

2003 Cognitive style in the service of language learning. System 31, 393-415.

Elder, Catherine and Diane Manwaring

2004 The relationship between metalinguistic knowledge and learning outcomes among undergraduate students of Chinese. Language Awareness 13 (3), $145-162$.

Elder, Catherine, Jane Warren, John Hajek, Diane Manwaring, and Alan Davies

1999 Metalinguistic knowledge: How important is it in studying a language at university? Australian Review of Applied Linguistics 22 (1), 81-95.

Ellis, Nick C.

1993 Rules and instances in foreign language learning: Interactions of explicit and implicit knowledge. European Journal of Cognitive Psychology 5 (3), 289-318.

1994 Consciousness in second language learning: Psychological perspectives on the role of conscious processes in vocabulary acquisition. AILA Review 11, $37-56$.

1996 Sequencing in SLA: Phonological memory, chunking, and points of order. Studies in Second Language Acquisition 18, 91-126.

2001 Memory for language. In Robinson, Peter (ed.), Cognition and Second Language Instruction. Cambridge: Cambridge University Press, 33-68.

2002a Frequency effects in language processing: A review with implications for theories of implicit and explicit language acquisition. Studies in Second Language Acquisition 24 (2), 143-188.

$2002 \mathrm{~b}$ Reflections on frequency effects in language processing. Studies in Second Language Acquisition 24 (2), 297-340.

2003 Constructions, chunking, and connectionism: The emergence of second language structure. In Doughty, Catherine J. and Michael H. Long (eds.), The Handbook of Second Language Acquisition. Malden, MA: Blackwell, 63-103.

2005 At the interface: Dynamic interactions of explicit and implicit language knowledge. Studies in Second Language Acquisition 27 (2), 305-352.

Ellis, Nick C. and Diane Larsen-Freeman

2006 Language emergence: Implications for applied linguistics. Applied Linguistics 27 (4), 558-589.

Ellis, Rod

2001 Introduction: Investigating form-focused instruction. Language Learning 51 (1), 1-46. 
2002 Does form-focused instruction affect the acquisition of implicit knowledge? Studies in Second Language Acquisition 24 (2), 223-236.

2004 The definition and measurement of L2 explicit knowledge. Language Learning 54 (2), 227-275.

2005 Measuring implicit and explicit knowledge of a second language: A psychometric study. Studies in Second Language Acquisition 27 (2), 141-172.

2006 Modelling learning difficulty and second language proficiency: The differential contributions of implicit and explicit knowledge. Applied Linguistics 27 (3), 431-463.

Ellis, Rod and Gary Barkhuizen

2005 Analysing Learner Language. Oxford: Oxford University Press.

Engel, Andreas K.

2003 Temporal binding and the neural correlates of consciousness. In Cleeremans, Axel (ed.), The Unity of Consciousness: Binding, Integration, and Dis-

Gabrielatos, Costas sociation. Oxford: Oxford University Press, 132-152.

2004 If-conditionals in ELT materials and the BNC: Corpus-based evaluation of pedagogical materials. Paper presented at the Corpus Linguistics Research

Goldberg, Adele E. Group meeting on 26 April 2004, Lancaster University.

1995 Constructions: A Construction Grammar Approach to Argument Structure. Chicago: University of Chicago Press.

1999 The emergence of the semantics of argument structure constructions. In MacWhinney, Brian (ed.), The Emergence of Language. Mahwah, NJ: Erlbaum, 197-212.

2003 Constructions: A new theoretical approach to language. Trends in Cognitive Sciences 7 (5), 219-224.

Gombert, Jean Emile

1992 Metalinguistic Development. Hemel Hempstead: Harvester.

Green, Peter S. and Karlheinz Hecht

1992 Implicit and explicit grammar: An empirical study. Applied Linguistics 13 (2), 168-184.

Hampton, James A.

2005 Rules and similarity - a false dichotomy. Behavioral and Brain Sciences 28 (1), 26.

$\mathrm{Hu}$, Guangwei

2002 Psychological constraints on the utility of metalinguistic knowledge in second language production. Studies in Second Language Acquisition 24 (3), $347-386$.

Hulstijn, Jan H.

2005 Theoretical and empirical issues in the study of implicit and explicit secondlanguage learning: Introduction. Studies in Second Language Acquisition 27 (2), 129-140.

Hulstijn, Jan H. and Rick de Graaff

$1994 \quad$ Under what conditions does explicit knowledge of a second language facilitate the acquisition of implicit knowledge? A research proposal. AILA Review 11, 97-112.

Jessner, Ulrike

1999 Metalinguistic awareness in multilinguals: Cognitive aspects of third language learning. Language Awareness 8 (3-4), 201-209. 
2006 Linguistic Awareness in Multilinguals: English as a Third Language. Edin-

Johnson, Keith burgh: Edinburgh University Press.

1996 Language Teaching and Skill Learning. Oxford: Blackwell.

Just, Marcel Adam and Patricia A. Carpenter

1992 A capacity theory of comprehension: Individual differences in working memory. Psychological Review 99 (1), 122-149.

Karmiloff, Kyra and Annette Karmiloff-Smith

2002 Pathways to Language: From Fetus to Adolescent. Cambridge, MA: Harvard University Press.

Kemmer, Suzanne and Michael Barlow

2000 Introduction: A usage-based conception of language. In Barlow, Michael and Suzanne Kemmer (eds.), Usage-Based Models of Language. Stanford,

Kemp, Charlotte CA: CSLI, vii-xxviii.

2001 Metalinguistic awareness in multilinguals: Implicit and explicit grammatical awareness and its relationship with language experience and language attainment. Unpublished doctoral dissertation, University of Edinburgh.

Klapper, John and Jonathan Rees

2003 Reviewing the case for explicit grammar instruction in the university foreign Krashen, Stephen D. language learning context. Language Teaching Research 7 (3), 285-314.

1981 Second Language Acquisition and Second Language Learning. Oxford: Pergamon.

1985 The Input Hypothesis: Issues and Implications. London: Longman.

Langacker, Ronald W.

1991 Concept, Image, and Symbol: The Cognitive Basis of Grammar. Berlin: Mouton de Gruyter.

1999 Grammar and Conceptualization. Berlin: Mouton de Gruyter.

2000 A dynamic usage-based model. In Barlow, Michael and Suzanne Kemmer (eds.), Usage-Based Models of Language. Stanford, CA: CSLI, 1-64.

Larsen-Freeman, Diane

2006 The emergence of complexity, fluency, and accuracy in the oral and written production of five Chinese learners of English. Applied Linguistics 27 (4), $590-619$.

Leow, Ronald P.

1997 Attention, awareness, and foreign language behavior. Language Learning 47, 467-505.

MacWhinney, Brian

1997 Implicit and explicit processes: Commentary. Studies in Second Language Acquisition 19, 277-281.

Markman, Arthur B., Sergey Blok, Kyungil Kom, Levi Larkey, Lisa R. Narvaez, C. Hunt Stilwell, and Eric Taylor

2005 Digging beneath rules and similarity. Behavioral and Brain Sciences 28 (1), 29-30.

McDonough, Steven

2002 Applied Linguistics in Language Education. London: Arnold.

McLaughlin, Barry

1995 Aptitude from an information-processing perspective. Language Testing 12, 370-387. 
Miyake, Akira and Naomi P. Friedman

1998 Individual differences in second language proficiency: Working memory as language aptitude. In Healy, Alice F. and Lyle E. Bourne (eds.), Foreign Language Learning: Psycholinguistic Studies on Training and Retention. Mahwah, NJ: Erlbaum, 339-364.

Miyake, Akira and Priti Shah

1999 Toward unified theories of working memory: Emerging general consensus, unresolved theoretical issues, and future research directions. In Miyake, Akira and Priti Shah (eds.), Models of Working Memory: Mechanisms of Active Maintenance and Executive Control. Cambridge: Cambridge University Press, 442-481.

Murphy, Gregory L.

2004 The Big Book of Concepts. Cambridge, MA: MIT Press.

Murphy, Raymond

1994 English Grammar in Use (2nd ed.). Cambridge: Cambridge University Press.

Nagata, Noriko and Virginia M. Swisher

1995 A study of consciousness-raising by computer: The effect of metalinguistic feedback on second language learning. Foreign Language Annals 28 (3), $337-347$.

Norris, John M. and Lourdes Ortega

2001 Does type of instruction make a difference? Substantive findings from a meta-analytic review. Language Learning 51 (1), 157-213.

Paradis, Michel

2004 A Neurolinguistic Theory of Bilingualism. Amsterdam: John Benjamins.

Pothos, Emmanuel M.

2005 The rules versus similarity distinction. Behavioral and Brain Sciences 28 (1), $1-49$.

Reber, Rolf

2005 Rule versus similarity: Different in processing mode, not in representations.

Reid, Joy M. (ed.)

Behavioral and Brain Sciences 28 (1), 31-32.

1998 Understanding Learning Styles in the Second Language Classroom. Upper

Renou, Janet M.

Saddle River, NJ: Prentice Hall Regents.

2000 Learner accuracy and learner performance: The quest for a link. Foreign

Robinson, Peter

Language Annals 33 (2), 168-180.

1995 Review article: Attention, memory, and the "noticing" hypothesis. Language Learning 45 (2), 283-331.

1997 Generalizability and automaticity of second language learning under implicit, incidental, enhanced, and instructed conditions. Studies in Second Language Acquisition 19, 223-247.

2003 Attention and memory during SLA. In Doughty, Catherine J. and Michael H. Long (eds.), The Handbook of Second Language Acquisition. Malden,

Roehr, Karen

2005 Metalinguistic knowledge in second language learning: An emergentist perspective. Unpublished doctoral dissertation, Lancaster University.

2006 Metalinguistic knowledge in L2 task performance: A verbal protocol analysis. Language Awareness 15 (3), 180-198. 
2007

Metalinguistic knowledge and language ability in university-level L2 learners. Applied Linguistics. doi: 10.1093/applin/amm037. URL: 〈http://applij. oxfordjournals.org/cgi/content/full/amm037?ijkey=1xNurNzW63Rt3Um\& keytype $=$ ref $\rangle$.

Roehr, Karen and Adela Gánem

2007 Metalinguistic knowledge in L2 learning: An individual difference variable.

Paper presented at Euro SLA on 13 September 2007, Newcastle University.

Rosa, Elena and Michael D. O’Neill

1999 Explicitness, intake, and the issue of awareness. Studies in Second Language Acquisition 21, 511-556.

Rosch, Eleanor, and Barbara B. Lloyd (eds.)

1978 Cognition and Categorization. Hillsdale, NJ: Erlbaum.

Rosch, Eleanor and Carolyn B. Mervis

1975 Family resemblances: Studies in the internal structure of categories. Cognitive Psychology 7, 573-605.

Sanz, Cristina and Kara Morgan-Short

2004 Positive evidence versus explicit rule presentation and explicit negative feedback: A computer-assisted study. Language Learning 54 (1), 35-78.

2005 Explicitness in pedagogical interventions: Input, practice, and feedback. In Sanz, Cristina (ed.), Mind and Context in Adult Second Language Acquisition: Methods, Theory, and Practice. Washington, DC: Georgetown University Press, 234-263.

Saporta, Sol

1973 Scientific grammars and pedagogical grammars. In Allen, J. P. B. and Pit

Corder (eds.), The Edinburgh Course in Applied Linguistics. London: Oxford

Schmidt, Richard W.

University Press, 265-274.

1990 The role of consciousness in SLA learning. Applied Linguistics 11, 129-158.

1993 Awareness and second language acquisition. Annual Review of Applied Linguistics 13, 206-226.

2001 Attention. In Robinson, Peter (ed.), Cognition and Second Language Instruction. Cambridge: Cambridge University Press, 3-32.

Schumann, John H.

1998 The neurobiology of affect in language. Language Learning 48 (s1), xi-341.

2004 The neurobiology of aptitude. In Schumann, John H., Sheila E. Crowell, Nancy E. Jones, Namhee Lee, Sara Ann Schuchert, and Lee A. Wood (eds.), The Neurobiology of Learning: Perspectives from Second Language Acquisition. Mahwah, NJ: Erlbaum, 7-22.

Segalowitz, Norman

2003 Automaticity and second languages. In Doughty, Catherine J. and Michael H. Long (eds.), The Handbook of Second Language Acquisition. Malden, MA: Blackwell, 382-408.

Shah, Priti and Akira Miyake

1999 Models of working memory: An introduction. In Miyake, Akira and Priti Shah (eds.), Models of Working Memory: Mechanisms of Active Maintenance and Executive Control. Cambridge: Cambridge University Press, 127.

Simard, Daphnée and Wynne Wong

2001 Alertness, orientation, and detection: The conceptualization of attentional functions in SLA. Studies in Second Language Acquisition 23, 103-124. 
Skehan, Peter

1998 A Cognitive Approach to Language Learning. Oxford: Oxford University Press.

Sloman, Steven

2005 Avoiding foolish consistency. Behavioral and Brain Sciences 28 (1), 3334.

Smith, Edward

2005 Rule and similarity as prototype concepts. Behavioral and Brain Sciences 28 (1), 34-35.

Sorace, Antonella

1985 Metalinguistic knowledge and language use in acquisition-poor environments. Applied Linguistics 6 (3), 239-254.

Sparks, Richard and Leonore Ganschow

2001 Aptitude for learning a foreign language. Annual Review of Applied Linguistics $21,90-111$.

Stankov, Lazar

2003 Complexity in human intelligence. In Sternberg, Robert J., Jacques Lautrey, and Todd I. Lubart (eds.), Models of Intelligence: International Perspectives. Washington, DC: American Psychological Association, 2742.

Stevick, Earl W.

1999 Affect in learning and memory: From alchemy to chemistry. In Arnold, Jane (ed.), Affect in Language Learning. Cambridge: Cambridge University Press, $43-57$.

Swain, Merrill

1998 Focus on form through conscious reflection. In Doughty, Catherine J. and Jessica Williams (eds.), Focus on Form in Classroom Second Language Acquisition. Cambridge: Cambridge University Press, 6481.

Swan, Michael

1994 Design criteria for pedagogic language rules. In Bygate, Martin, Alan Tonkyn, and Eddie Williams (eds.), Grammar and the Language Teacher. New York, NY: Prentice Hall, 45-55.

1995 Practical English Usage (2nd ed.). Oxford: Oxford University Press.

Taylor, John R.

2002 Cognitive Grammar. Oxford: Oxford University Press.

2003 Linguistic Categorization (3rd ed.). Oxford: Oxford University Press.

Tomasello, Michael

1998 Introduction: A cognitive-functional perspective on language structure. In Tomasello, Michael (ed.), The New Psychology of Language: Cognitive and Functional Approaches to Language Structure (Vol. 1). Mahwah, NJ: Erlbaum, vii-xxiii.

2003 Constructing a Language: A Usage-Based Theory of Language Acquisition. Cambridge, MA: Harvard University Press.

Tomlin, Russell and Victor Villa

1994 Attention in cognitive science and second language acquisition. Studies in

Towell, Richard Second Language Acquisition 16, 183-203.

2002 Design of a pedagogical grammar. URL: 〈http://www.lang.ltsn.ac.uk/ resources/goodpractice. aspx?resourceid $=410\rangle$. 


\section{K. Roehr}

Ungerer, Friedrich and Hans-Jörg Schmid

1996 An Introduction to Cognitive Linguistics. London: Longman.

VanPatten, Bill

1996 Input Processing and Grammar Instruction in Second Language Acquisition. Norwood, NJ: Ablex.

VanPatten, Bill (ed.)

2004 Processing Instruction: Theory, Research, and Commentary. Mahwah, NJ: Erlbaum. 